\title{
Higher Education Funding: \\ A Decade of Changes
}

\author{
THIERRY CHEVAILLIER and JEAN-CLAUDE EICHER \\ IREDU-CNRS, Université de Bourgogne
}

Article publié dans Higher Education in Europe, vol.27, $n^{\circ} 1-2,2002$, pp.89-99

DOI: $10.1080 / 0379772022000003242$

\begin{abstract}
:
The authors, two French specialists on the financing of higher education, reflect on the conclusions they drew in an article, "Rethinking the Financing of Post-Compulsory Education", which they published in this review ten years ago. ${ }^{1}$ As they foresaw, higher education funding became increasingly based on mixed sources with students being required to pay a greater share of the costs of their education. But mechanisms to make cost sharing increasingly equitable have been refined. At the same time, the determination of actual costs per institution, per course programme, and even per course has become increasingly accurate, and funding is increasingly taking into account the verdict of performance indicators of various kinds. The funding of research is being increasingly differentiated from funding for teaching/learning. Across the board, higher education institutions have had to do more for less.
\end{abstract}

Ten years ago, we published an article in Higher Education in Europe (Eicher and Chevaillier, 1992) in which we analyzed the funding of "post-compulsory" education, in an attempt to foresee the developments that were going to take place as a result of the crisis situation with which it was confronted. We were particularly aware of the problems being caused by the unprecedented expansion of the student population which had challenged traditional funding modes, at a time when public trust in the capacity of education to promote economic growth was seriously shaken.

Since then, initiatives multiplied and a number of changes occurred. The 1990s were rich in experiments, innovations, and debates. ${ }^{2}$

Under the pressure of the international financial community and the expansion of the phenomenon of the globalization of economies, African, Latin American, and Asian countries, as well as a number of countries "in transition" introduced, fostered, or allowed the development of a private sector of "tertiary" education.

Confronted with a decline in revenue or the progressive growth of social expenditures, many countries, at very different levels of development, tried to restrain the expansion of the public funding of education in general, and of higher education, in particular. The solutions that imposed themselves were to reduce the costs and to impose their sharing with those that partly benefit from education and training:

- The cost per student related to the GDP per capita decreased in most developed countries. Between 1995 and 1998, only Italy and Greece, among the OECD countries, witnessed an increase in the expense per student that was greater than the revenue per capita (OECD/CERI, 2001).

- Private expenditure for higher education increased in seventeen OECD countries, sometimes a great deal, as in Turkey, Portugal, and Italy. They visibly decreased in only three countries, Mexico, Austria, and the Czech Republic.

- In most countries, tuition fees were introduced where they did not exist before and increased where they already existed. Institutions were forced, by the stagnation or decrease of public funding, to identify new resources or to develop resources neglected up until then.

The increasing recourse to family resources in the context of the democratization of higher education

1 Specifically in Volume 17, No. 1, pp. 6-32.

2 A synthesis of those development $\mathrm{s}$ was reflected in the report, Higher Education, the Lessons of Experience, published in 1994 by The World Bank, and in the documents of the World Conference on Higher Education organized by UNESCO in 1998. 
made clear the need for the development or the reorganization of student aid systems. Considerations of efficiency and equity induced a reassessment of aid systems, conceived in the context of a more élitist higher education system.

However, the extent of the redistribution of public funds versus private funds has been quite limited on a global scale, even though, with regard to higher education, it has exceeded the standards that one could observe for other levels of education.

\section{The development of the private funding of higher education}

An increase of private resources for higher education can be achieved through the establishment or expansion of private institutions that are partially or entirely financed from contributions by students and their families, as well as by the mobilization of new resources by the public sector, among which user contributions play a primary role. These different methods, regrouped in a simplistic manner under the category of "privatization", deserve being distinguished, one from the others.

\section{User-Funding}

The first means by which to diversify the sources of higher education is undeniably through student contributions to the costs of their education. This participation is justified by the fact that education brings some advantages to those benefiting from it. The benefits that they derive from it at a personal level are substantial: cultural and intellectual gains, difficult to calculate, but most of all, advantages in terms of income that one can evaluate by comparing the salaries of employees having attained different awarded degrees and levels of education.

Even though there are social gains that also have an effect on the whole of society and that can justify the contribution of the community which allocates a part of its resources, the individual gains obtained through education cannot be contested. For this reason, international bodies, such as the World Bank, which are involved in the funding and development of education, consider that it is necessary to encourage "cost-sharing", i.e., the contribution of the user to a part of the cost of his or her education. User-funding may vary in form, function of the moment when it appears and of its incorporated degree of redistribution. At one end of the spectrum of possible solutions, one finds universities that charge tuition fees to some students, covering the whole cost of the programmes in which they are enrolled, as well as the cost of accommodation and meals. The logic is that of the market, whereby the production costs must be covered by a fee paid by the customer. Other ways and means exist at the other end of the spectrum, such as the degree tax that graduates might have to pay after they enter the labour market, so as to reimburse the community for a part of their educational expenses that the latter has covered.

\section{Tuition Fees}

We should recall, in the first place, the distinction between tuition fees and upkeep costs (student maintenance). Very few countries, nowadays, can assure free tuition to all of their students, while also covering their maintenance expenses. These costs are sometimes indirectly subsidized by the community, which covers certain expenses related to student accommodation or meals. Increasingly, universities are charging fees for the services that they provide to students. In the interests of good management, they measure the precise costs of these services, so as to avoid underestimating them and thus reducing the resources intended for instructional activities.

Until the 1980s, a clear distinction was made between countries in which higher education institutions charged substantial tuition fees and those that applied the principle of free tuition higher education. In Continental and Northern Europe, the only contributions asked of students were contributions of a social or administrative nature (enrollment fees, examination fees, sports or union dues) or for specific 
services, other than educational services.

In the latter countries, the question of tuition fees stopped being taboo, and a public debate opened. Tuition fees have been introduced or greatly increased in a majority of these countries, particularly Spain, the Netherlands, Belgium, and Ireland in the 1980s, Portugal, Italy, the United Kingdom in the 1990s, Austria in 2000, not to mention the Central and Eastern European countries, in which they were introduced everywhere.

However, the controversy over the legitimacy of tuition fees is far from having subsided, as shown by the very weak increase observed in France since the mid-1980s or their turn-over, following a change in political majority in certain countries, i.e., Portugal and Ireland, as well as in Scotland, after the devolution law. Still, in these countries, the principle of tuition fees has been established and remains in effect. Only certain exemptions or deferment of payment to the end of studies for certain categories of students are envisaged. Thus, in Ireland (Clancy and Kehoe, 1999), a student who repeats a year of undergraduate studies or who is registered in third cycle studies must pay higher tuition fees.

Outside Europe, the general tendency is to raise these fees, particularly in Latin America and India. Changes of régime have brought with them the introduction of tuition fees, as in the case of China.

\section{Selective Tuition Fees}

In certain countries which did not adopt general tuition fees, other fees applying to specific student categories have been instituted. Some are incentive in character, as in the Baden-Würtemberg Land, where, beginning in 1997, students who remain enrolled in a university beyond the average length of studies, must pay a fee of 1,000 DM per semester. Other categories of students are required to pay full cost tuition fees. These may include foreign students enrolled in specific programmes or admitted beyond the number of places financed from the public budget. Thus, Australian universities are permitted, within certain limits, to enroll students paying the full tariff. In the United Kingdom, foreigners may be enrolled under similar conditions beyond the number of places financed from the public budget. One can witness in most countries the development of lifelong learning or short programmes in the fields for which there is high demand (Business Management, Computer Sciences, etc.). These programmes may lead to the charging of a freely fixed tuition fee set by competing institutions. In Hungary, the 1996 Law on Higher Education distinguishes

two sorts of course programmes, those that are financed by the State, and those that imply payment of tuition fees, which means that within the public universities there actually coexist two student categories.

This possibility is sometimes viewed as a necessity by institutions in countries in which higher education, traditionally financed from public resources, cannot develop or maintain itself because of the weak development or the disorganization of their fiscal administration. In the Russian Federation, the government is incapable of assuming the full costs of higher education (OECD/CERI, 1999). Tax levy is problematic and is directed mainly at enterprises. Universities are allowed to enroll tuition feepaying students in a proportion of up to 25 percent of their full capacity, and the absence of supervision often allows them to exceed this limit.

In sub-Saharan Africa, a trend of substantial increases in tuition fees is in progress in countries like Uganda, South Africa, Nigeria, and, very recently, Togo. The actual models vary and eventually take the shape of a dual system, whereby the best candidates are admitted free, whereas other students, paying quite high fees, are also enrolled (e.g., Uganda and Nigeria). Universities and their departments are being encouraged to create new programmes in order to tap into this solvent demand, while keeping hold of a part of the new resources obtained in this way and directing them to enhance the salaries of faculty members (Mayanja, 2001).

\section{Deferred Payment of Tuition Fees}

Two main means have been proposed to defer the contributions of students to the funding of their education: student loans, used to pay tuition fees, and the reimbursement by fiscal means of sums contributed by the community (the "Diploma Tax"). 
In Australia, the Higher Education Contribution Scheme, introduced in 1989, attracted great worldwide interest. The method consists in introducing relatively high tuition fees (about 20 percent of the total costs of instruction), while deferring their payment for students who so request until after graduation. (Students who wish to do so can pay their tuition fees at the beginning of each academic year, thus benefiting from a 25 percent discount.) The reimbursement begins when the income of a former student has reached a certain level (corresponding to the average taxable income of the country), through payments proportional to income, made through the fiscal administration, in addition to the taxes normally paid by every taxpayer. The experience gained by this plan suggests that it confers real advantages (Chapman, 1997). The reimbursement rate, compared to other student loan schemes, is excellent. Contrary to all predictions, the introduction of this system has not reduced the level of enrollment in higher education.

This Australian example inspired Scotland, where its Parliament, newly empowered by the devolution process, chose to split off from the rest of the United Kingdom and to adopt a system of deferredpayment tuition fees. As per the Cubie Report, the decision has been taken to begin deferring as of 2001, the collection of the student contribution until after graduation (what was presented as a suppression of tuition fees), offering each student the choice to pay in cash or on credit. For those choosing the credit system, the conditions will be those of student loans ("maintenance loans"), which will allow them eventually to combine the latter with loans already contracted during their studies.

\section{Sale of Services by the Institutions}

The sale of services, whether or not they are directly bound to the educational activity of the institution, increasingly represents a significant part of the resources of higher-education institutions. For the North American universities, it represents about 20 percent of their resources, irrespective of whether the institutions are private or public ones. Increasingly, particularly in Africa, higher education institutions may charge full cost fees for students services, particularly for food and lodging. One also notices, particularly in Europe, that certain universities are beginning to show signs of an entrepreneurial spirit (Clark, 1998) that is encouraging them to vary their funding sources and therefore to reduce their dependence on the community. They have created new entities that are intended to act as interfaces with the economic and social environment. These entities are professionally managed, according to a commercial logic similar to that of the corporations with which they are in contact. They are charged with the marketing of research results, and of valorizing the technological or experimental transfers taking place in universities. Such entities, or the universities themselves, may offer lifelong professional education. This activity, that generates supplementary financial resources, also fuels the teaching and research sectors related to the traditional missions of these institutions.

Universities can also obtain supplementary resources through the export of education programmes. Notwithstanding the enrollment of foreign students, American, British, and Australian universities are opening branches in Asian and in Central and Eastern European countries that offer courses that are in great demand. They may also authorize franchised institutions to deliver their degrees, receiving in exchange fees and royalties. The sale of instructional programmes and educational resources is developing, with the help of the new information and communication technologies.

\section{Income from Patrimony}

Even in countries having the most highly developed institutional patrimony, the returns that the individual higher education institutions receive from it remain small. In the United States, this return represents an average of 1 percent of the income of state universities and 7 percent of that of private universities (Vossensteyn and Canton, 2002: 67), but with very strong disparities. [In 1991, a dozen universities earned more than a billion dollars from this source, the global financial patrimony of universities being estimated at 72 billion (NCES, 1994).]

Incomes from patrimony could acquire a much higher level of importance if a current proposal, being made by the Conservative Party of the United Kingdom, were implemented. The proposal calls for 
endowing all the higher education institutions, once and for all, with financial resources, so that their functioning and their investments can be assured from the income that the investment of these resources would bring (Funding Options Review Group, 2001). Despite proposals to adopt this system, it is unlikely that it could ever replace the current system of recurrent public funding. The calculations made by Universities UK estimated the necessary sum for the endowment of all British universities to exceed $£ 100$ billion sterling.

\section{Grants and Donations}

If donations are encouraged by the grant of fiscal advantages, they correspond to a reduction in public resources. To donors, they present the advantage of their being able to determine the recipients of their largesse, something which they cannot do with the taxes they pay. To recipients, such a system has the advantage of making the results dependent on the efforts exerted to achieve them. However, the efforts in question represent a cost drawn against the amounts collected. The situation is quite similar to that of the French Tax for Instruction (Taxe d'apprentissage), a salary tax which can be covered by enterprises by transferring certain remittances to teaching institutions of their choice.

\section{Limits to the Diversification of Resources}

The tendency for the amount of private funding invested in education to expand is not global. Some countries have witnessed increasing public funding (OECD/CERI, 2001), as for example in the cases of Japan, Republic of Korea, Mexico, and Ireland. In some of these countries, the phenomenon can be explained by the existence of new public funding sources, such as European funding in the case of Ireland. In others, deliberately formulated policies have been particularly aimed at bringing about greater equity in access to higher education. In most cases, the limitation of private resources has been caused by economic or social constraints related to the developmental and organizational levels of the countries concerned.

When austerity in public policy formulation is at the origin of the resource diversification initiatives undertaken in higher education at institutional or systemic level, the impact on universities has been harshest in countries in which such diversification is limited (John- stone, 2001).

The capacity of students and their families to support some of the costs of their education may encounter certain limits. First of all, parents are not always able or, even if they possess the necessary resources, willing to contribute to the education of their children, the latter situation raising the question of the financial autonomy of young adults. On the other hand, the characteristics of labour markets do not always enable students to contribute themselves to their upkeep or education, in conditions compatible with the normal pursuit of the studying and learning process. Student loans or deferred contribution systems require a further development of the fiscal and financial system, which is only present in the most advanced countries.

The diversification of institutional resources also encounters limits within national economic and social environments. The disciplines within which enterprises are most likely to look for collaborators or assistance from universities are very often those that are the most underrepresented within the universities in Third World countries. They are also subject to the brain drain phenomenon, having a hard time holding on to locally trained specialists or attracting back home those educated abroad.

Finally, philanthropy does not represent a substantial funding source, except in countries in which higher education is firmly implanted and where there are incentives for private wealth to be invested in them. Usually, a heavy fiscal system is needed in order to encourage donations.

\section{Development of private education}

Private education is sometimes viewed as the palliative allowing the rapid expansion of higher education in order to meet exploding demands. Such is the case in many Asian and Latin American 
countries, where private institutions emerged, particularly in low-cost and high-demand education sectors. Such expansion, however, can raise questions as to quality, particularly when tuition fees are restricted by the state to an insufficient level, as is the case in the Philippines. It also raises questions of equity in countries in which low-income candidates who have not been admitted to public institutions must pay high enrollment fees in the private sector, as in India, Chile, or Korea.

It was with the aim of preventing such perverted effects that the Japanese authorities were forced to strongly increase public subsidies for private institutions in the late 1970s. Such a movement did not occur in Korea. Here the private institutions, that at present enroll 75 percent of the total numbers of students, are 95 percent dependent on enrollment fees. Such fees cover only 40 percent of the resources of public institutions.

In other countries, mainly in Europe and in North America, private higher education is well established and competes in terms of quality with public higher education. In these countries, the private institutions are subsidized by the public authorities, sometimes to the same extent as the public institutions are, as in Belgium and the Netherlands. In the United States, such subsidies, although not negligible, are smaller and have declined over the last decades. Representing 20 percent of institutional income in 1980, they only represented 16 percent in 1995.

\section{Modes of public funding}

Regardless of its size, public funding exerts a certain influence on the functioning of higher education institutions, according to the manner in which the funds reach them. For the public authorities, this reality has resulted in a constant search for the best funding procedures that stimulate the types of behaviour considered as the most desirable for the actors concerned. The "piloting" of higher education systems by the encouragement of appropriate financial mechanisms was the watchword of policies adopted in many countries.

\section{Activity-Linked Funding}

More and more frequently, public funding of higher education has been linked to indicators of the volume of institutional activity. This option is the first one that comes to mind when, in a country in which state finances constitute the greatest proportion of the costs of education, the authorities decide to rationalize the higher education resource distribution procedures and to abandon a routine or traditional method of distribution.

The activity can be approached by the volume of resources used - the "inputs" of the production process. Funding models are elaborated that take into account staff salaries and equipment used. This method has the defect that it reproduces the historical inequalities that led to existing differences in means.

Another view on inputs leads to a consideration of enrolled students as a better indicator of activity. Most European public funding systems are drawing upon this option (Vossensteyn, et al., 1998). The number of enrolled students, in the most complex models, is weighted against the given study level and the discipline in order to take into consideration the varying teaching/learning conditions.

The most extreme case of a funding model based on activity measured in terms of student numbers is certainly the system of educational coupons or "vouchers" that has been extolled over the last decades as one of the most efficient means to introduce market flexibility and dynamism into the educational sector. The families or the students receive vouchers that enable them to pay tuition fees at the institutions of their choice. The institutions in question then cash in the vouchers obtained. Resources are thus directed by the recipients of education toward the institutions that best suit their needs. The voucher system, that was tested in secondary schools in several states in the United States, has had little success in higher education. This lack of success has resulted from the diversity of types of institutions and of study fields, some requiring greater funding than others. Thus, student choices need to be determined before a specific value can be given to vouchers or a base level value imparted to all 
vouchers that given families can supplement with a further contribution. At any rate, public funding systems based on the number of students enrolled in different fields and in different types of institutions are much simpler to implement and have precisely the same effect as the use of educational vouchers, so far as freedom in choosing one's institution and field of study are concerned.

\section{Results-Based Funding}

Given a situation in which each student is totally free as to choice of studies, one can still not assume that the funds will go to the most "effective" institutions unless the information made available to young people and their families is sufficient so that they might be able to identify the most appropriate institution and field. Given imperfect information, freedom of choice does not guarantee that proper funding assures proper performance.

Some countries have managed to link fairly tightly together public funding for education and for institutional performance. In 1993, the Netherlands introduced a performance criterion in the funding formula for universities, assigning a proportion of total funding on the basis of the numbers of diplomas awarded. In order not to destabilize the institutions, this element, that initially represented 20 percent of the total, was intended to progressively increase until it became the single criterion for the allocation of educational funding. The method was subsequently reviewed when it became clear that the competition among universities for students risked triggering too large a fluctuation in their resource levels (Koelman, 1998). Beginning with 1998, the results, instead of being used in a retrospective manner, are applied in a prospective manner in the setting of mid-term objective-based contracts that are negotiated with each university.

In Denmark, performance-based funding takes the shape of the "Taximeter"; i.e, the grant allocated to each institution is calculated, not on the basis of the number of enrolled students, but according to the number of students who pass their examinations and progress normally toward the award of their degrees.

\section{Institutional Autonomy and Financing}

Two contradictory tendencies could be confirmed in the 1990s: a more intense division between the funding of research and of teaching and an effort to globalize public endowments. Everywhere in Europe, with the exception of Germany and Sweden, and to some extent the Netherlands, research is increasingly being anticipated and funded according to criteria and procedures distinct from those used for education. This evolution, that is contrary to the Humboldtian academic tradition, is giving rise to internal tensions within institutions and is contributing to the increasing of institutional differentiation.

The division of funding into several isolated sectors, that is contrary to the affirmation of institutional autonomy and responsibility, also leads to an incorrect use of resources and to an inability to achieve the compromises necessary for the development of higher education institutions are indeed their very sources of survival. ${ }^{3}$

To reconcile the necessary autonomy of institutions and their responsibilities vis-à-vis public contributors, certain countries, i.e., Denmark and the Netherlands, followed by France (Chevaillier, 1998), introduced in their funding procedures the negotiation of multi-year contracts based on a strategic project elaborated by each university. This approach, a special adaptation of the so-called "new public management", allows the public authorities to designate national priorities, while offering institutions strong incentives to anticipate the future and to improve their management.

But this preoccupation to assure the steering of the education system is not shared by all politicians. Let us recall the proposal of the Conservative Party of the United Kingdom to remove certain universities from the public funding system, while assuring them a patrimony, the incomes from which would be sufficient to assure their perpetual functioning. 


\section{Student Aid}

In the countries in which tuition fees for higher education were traditionally non-existent or very small, their introduction and substantial increase, particularly in Europe, required the reassessment of student assistance levels to take into account the rise in the costs of education. Such is the case in the Netherlands, in which each student receives a base allowance which largely exceeds the amount which must be spent on tuition fees, and in which the least financial well-off students benefit from a supplementary grant that allows them to cover their living costs.

In all the countries of the world, and particularly in Europe, a debate is still raging with regard to student aid level and means of delivery. There are two opposing points of view. One holds that the student should be autonomous, a view that prevails in Scandinavian countries. The other one holds that it is necessary to take into consideration the resources of parents in order to determine the dimension of the public aid to be granted.

In several countries, in which the tuition fees are very high, certain aid policies have been developed by the institutions themselves or by charitable foundations in order to provide a supplement to public assistance. In the United States, in particular, in order to attract the best students, private universities having prohibitive tuition fees have established a private student aid system that they finance partly from the tuition fees they charge. In this manner, they bring about a degree of redistribution that is supplementary to the aid system of the federal government. Thus, the escalation of tuition fees and the costs of higher education have been made tolerable for society, even though costs have continued to escalate.

\section{Were forecasts achieved?}

Putting into balance the observable tendencies of the early 1990s that we cited in our 1992 article (Eicher and Chevaillier, 1992), we can today call attention to a mixed higher education funding system that combines both public and private resources, while retaining the required equity. Substantial tuition fees, accompanied by student benefits based on social criteria, enable most underprivileged students to cover these costs and a part of their living expenses. Publicly guaranteed student loans require the recipients - the students themselves - to assume responsibility for a part of the costs of their education. Basic public institutional funding allocated according to stable methods remains sufficiently motivating to stimulate an improvement in performance and to make the institutions increasingly autonomous and responsible. There is an increased implication on the part of the corporate sector in the education of a highly qualified work force, either through voluntary contributions or by means of new types of compulsory levying. Such a vision would imply certain reverse movements for countries having higher education systems that were radically different from those posited.

In Europe, the debate on the funding of higher education is far from being exhausted. In the United Kingdom, for example, the electoral programmes of different political parties offer a large variety of options and philosophies: introduction of a graduate tax, tuition fees according to field of study, fee differentiation set by universities, or even the replacement of public funding by a single capital endowment.

Recourse to tuition fees is expanding, but the very principle of these fees is not acceptable to all observers, even though one can notice signs of change in public attitudes in the Scandinavian countries and in Germany. However, the apparently successful experiments in the deferment of student contributions until their entry into the labour market, as in the Australian system of higher education, has opened the way to a better distribution of loads between the community and the individual.

The inequitable character of undifferentiated student aid seems also to be increasingly recognized. Thus one observes convergent reforms in student financial support policies. Increasingly, allowances and grants are being accorded on the basis of individual situations and no longer by virtue of simply 
being a student. The development of student loan systems may permit the reallocation of public monies toward job creation, thus reinforcing equity in access to higher education.

The convergence toward a mixed funding system gives rise to a reversal of evolution in countries that were initially placed in different situations. Such a situation gives the impression of confusion to the casual observer. When the State appears to be withdrawing from the higher education sector and to be abdicating its responsibilities, it may, in fact, be choosing other means of action and attempting to better define its role as the guarantor of social cohesion.

Thus, the globally observed, but relatively modest, redistribution of the funding effort for higher education from the public to the private sector can mask two important phenomena: convergence toward a mixed funding system and the transformation of public modes of intervention.

\section{REFERENCES}

CHAPMAN, B. J. "Conceptual Issues and the Australian Experience with Income Contingent Charges for Higher Education”, Economic Journal 107442 (1997): 738-751.

CHEVAILLIER, T. "Moving away from Central Planning: Using Contracts to Steer Higher Education in France", European Journal of Education 331 (1998).

CLANCY, P., and KEHOE, D. "Financing Third-level Students in Ireland", Student Costs and Financing, Special Issue, European Journal of Education 342 (March 1999).

CLARK, B. R. Creating Entrepreneurial Universities: Organizational Pathways of Transformation. Oxford, New York: International Association of Universities and Pergamon, 1998.

EICHER, J.-C. and CHEVAILLIER, T. "Rethinking the Financing of Post-Compulsory Education", Higher Education in Europe 171 (1992): 6-32.

FUNDING OPTIONS REVIEW GROUP. New Directions for Higher Education Funding. London: Universities UK, 2001.

JOHNSTONE, D. B. Responses to Austerity: The Imperatives and Limitations of Revenue Diversification in Higher Education. Buffalo: State University of New York at Buffalo, 2001.

KOELMAN, J. B. J. "The Funding of Universities in the Netherlands: Developments and Trends", Higher Education 35 (1998): 127-141.

MAYANJA, M. K. "Makerere University and the Private Students Scheme", International Higher Education 25 (Fall) 2001.

NCES. Digest of Education Statistics. Washington, D.C.: National Center for Educational Statistics, US Department of Education, 1994.

OECD/CERI. Examen des Politiques nationales d'éducation: Enseignement tertiaire et recherche en Fédération de Russie. Paris: Organization for Economics Co-operation and Development - The Centre for International Research and Studies, 1999.

OECD/CERI. Regards sur l'éducation - les indicateurs de l'OCDE. Tables B 1.2 and B 1.3. Paris: Organization for Economic Co-operation and Development-The Centre for International Research and Studies, 2001.

SANYAL, B. C. Innovations dans la gestion des universités. Paris: IIEP, 1997.

THE WORLD BANK. Higher Education: The Lessons of Experience. A World Bank Development Practice Paper. Washington, D.C.: The World Bank, 1994.

VOSSEnSteYN, J. J., JONGBLOED, B. W. A., and KOELMAN, J. B. J. University Funding Mechanisms: A Comparative Analysis of the Funding of Universities in Eight Western European Countries. Enschede: University of Twente, 1998.

VOSSENSTEYN, J. J., and CANTON, E. Tuition Fee Differentiation and Selectivity in the US. Enschede: CHEPS, and The Hague: CPB, 2001. 